\title{
Novel Voltage-Mode Universal Filters Using Two Current Conveyors
}

\author{
Ro-Min Weng, Jiunn-Ru Lay, Chih-Lung Lin, and Maw-Huei Lee \\ Rm. 329, Department of Electrical Engineering, National Taiwan University, \\ No.1 Sec.4, Roosevelt Rd.,Taipei 106, Taiwan, R.O.C. \\ Tel No:886-2-23635251 Ext. 329, Fax No: 886-2-23638247 \\ e-mail: d82003@,ccsun4.ee.ntu.edu.tw
}

\begin{abstract}
A novel configuration for realizing voltage-mode universal biquad filters with three inputs and two outputs is presented. The configuration uses only two secondgeneration current conveyors and four passive RC elements. The active and passive sensitivities are quite small. Simulation results that confirm the theoretical analysis are obtained.
\end{abstract}

\section{Introduction}

Current-mode circuits have been receiving significant attention because they have the potential advantages of accuracy and wide bandwidth over their voltage-mode counterparts [1] . A number of currentmode amplifiers have been introduced to realize voltagemode universal filters with three inputs and one output [2]-[6]. Despite the number of active components, those voltage-mode universal filters needed at least five or six passive elements.

Among those current-mode amplifiers, secondgeneration current conveyors (CCIIs) are found useful to realize voltage-mode biquad filters. Over the past few years, several universal filter schemes employing only two CCIIs have been developed [7]-[9]. Horng et al. [8] proposed the filter using only four passive RC elements.

We propose a novel configuration for realizing voltage-mode universal biquad filters using only two second-generation current conveyors. The configuration provides three inputs and two outputs employing four passive elements. A number of universal filters can be obtained from the configuration. The proposed filters can realize highpass, bandpass, lowpass, notch, and allpass filters without changing circuit topology and elements The active and passive sensitivities are quite low. PSpice simulation are given to verify the theoretical analysis.

\section{Circuit Deseription}

The port relations of a CCII can be shown as

$$
\left[\begin{array}{l}
v_{x} \\
i_{z} \\
i_{y}
\end{array}\right]=\left[\begin{array}{ccc}
1 & 0 & 0 \\
0 & \pm 1 & 0 \\
0 & 0 & 0
\end{array}\right]\left[\begin{array}{c}
v_{y} \\
i_{x} \\
v_{z}
\end{array}\right]
$$

where the plus and minus signs denote CCII + and CCII-, respectively. The network symbol and nullor model of CCII \pm are shown in Fig. 1.

The proposed configuration shown in Fig.2 has three inputs and two outputs. By a routine circuit analysis, the transfer functions of two outputs are given by the following equations:

$$
\begin{aligned}
& V_{o 1}=\frac{Y_{1} Y_{2} V_{i 1}+2 Y_{2} Y_{4} V_{i 2}+2 Y_{3} Y_{4} V_{i 3}}{Y_{1} Y_{2}+2 Y_{2} Y_{4}+2 Y_{3} Y_{4}} \\
& V_{02}=\frac{-Y_{1} Y_{3} V_{i 1}+\left(Y_{1}+2 Y_{4}\right)\left(Y_{2} V_{i 2}+Y_{3} V_{i 3}\right)}{Y_{1} Y_{2}+2 Y_{2} Y_{4}+2 Y_{3} Y_{4}}
\end{aligned}
$$

According to the nullor model, the first novel voltagemode universal filter as shown in Fig.3 is presented for $\mathrm{Y}_{1}=\mathrm{sC}_{1}, \mathrm{Y}_{2}=\mathrm{sC}_{2}, \mathrm{Y}_{3}=1 / \mathrm{R}_{3}$, and $\mathrm{Y}_{4}=1 / \mathrm{R}_{4}$. The universal filter, which is called Circuit A, comprises only two CCIIs, CCII+ and CCII-. The transfer functions of two output terminals, $\mathrm{V}_{\mathrm{o} 1}$ and $\mathrm{V}_{\mathrm{o} 2}$, can be expressed as

$$
\begin{aligned}
& V_{o 1}=\frac{s^{2} C_{1} C_{2} R_{3} R_{4} V_{i 1}+2 s C_{2} R_{3} V_{i 2}+2 V_{i 3}}{s^{2} C_{1} C_{2} R_{3} R_{4}+2 s C_{2} R_{3}+2} \\
& V_{02}=\frac{-s C_{1} R_{4} V_{i 1}+\left(s C_{1} R_{4}+2\right)\left(s C_{2} R_{3} V_{i 2}+V_{i 3}\right)}{s^{2} C_{1} C_{2} R_{3} R_{4}+2 s C_{2} R_{3}+2}
\end{aligned}
$$

From Equations ( $3 \mathrm{a}$ ) and ( $3 \mathrm{~b}$ ), five kinds of biquad filters can be realized. They are summarized as follows:

(i) If $\mathrm{V}_{\mathrm{i} 2}=\mathrm{V}_{\mathrm{i} 3}=0$ (grounded), a second-order highpass filter can be obtained from $V_{o 1}$ and a second-order bandpass filter can be obtained from $\mathrm{V}_{\mathrm{o} 2}$.

(ii) If $\mathrm{V}_{\mathrm{il}}=\mathrm{V}_{\mathrm{i3}}=0$ (grounded), a second-order bandpass filter can be obtained from $V_{o l}$.

(iii) If $\mathrm{V}_{\mathrm{i} 1}=\mathrm{V}_{\mathrm{i} 2}=0$ (grounded), a second-order lowpass filter can be obtained from $V_{o l}$.

(iv) If $V_{i z}=0$ (grounded) and $V_{i 1}=V_{i 3}=V_{i n}$, a secondorder notch filter can be obtained from $Y_{\text {ol }}$ and a lowpass filter can be obtained from $V_{\text {oz }}$.

(v) If $V_{i 1}=-V_{i 2}=V_{i 3}=V_{i n}$, a second-order allpass filter can be obtained from $V_{o 1}$.

(vi) If $\mathrm{V}_{\mathrm{i}}=0$ (grounded) and $\mathrm{V}_{\mathrm{il}}=\mathrm{V}_{\mathrm{i} 2}=\mathrm{V}_{\mathrm{in}}$, a secondorder highpass filter can be obtained from $V_{02}$ with matching condition $C_{1} R_{4}=2 C_{2} R_{3}$

This universal filter is particularly attractive for realizing lowpass filter obtained from $V_{o l}$ because two 
capacitors are grounded. The natural frequency $\omega_{0}$ and quality factor $Q$ are given by

$$
\omega_{0}=\sqrt{\frac{2}{C_{1} C_{2} R_{3} R_{4}}} \text {, and } Q=\sqrt{\frac{C_{1} R_{4}}{2 C_{2} R_{3}}}
$$

The natural frequency $\omega_{0}$ can be controlled by $R_{3}$ or $R_{4}$. Moreover, the quality factor $\mathrm{Q}$ can be controlled by the ratio of $R_{4} / R_{3}$ or $C_{1} / C_{2}$.

The second universal filter also shown in Fig. 3 is called Circuit B. Its transfer functions, natural frequency $\omega_{0}$, and the quality factor $Q$ are the same as those of Equations (3a), (3b), and (4), respectively.

If we exchange the $\mathrm{RC}$ elements of Circuit $\mathrm{A}$, a new universal filter called Circuit $C$ in Fig. 3 can be achieved. Its transfer functions, natural frequency $\omega_{0}$, and the quality factor $\mathrm{Q}$ are given as

$$
\begin{gathered}
V_{o 1}=\frac{2 s^{2} C_{3} C_{4} R_{1} R_{2} V_{i 3}+2 s C_{4} R_{1} V_{i 2}+V_{i 1}}{2 s^{2} C_{3} C_{4} R_{1} R_{2}+2 s C_{4} R_{1}+1} \\
V_{o 2}=\frac{-s C_{3} R_{2} V_{i 1}+\left(1+2 s C_{4} R_{1}\right)\left(V_{i 2}+s C_{3} R_{2} V_{i 3}\right)}{2 s^{2} C_{3} C_{4} R_{1} R_{2}+2 s C_{4} R_{1}+1} \\
\omega_{0}=\sqrt{\frac{1}{2 C_{3} C_{4} R_{1} R_{2}}} \text {, and } Q=\sqrt{\frac{C_{3} R_{2}}{2 C_{4} R_{1}}}
\end{gathered}
$$

The natural frequency $\omega_{0}$ can be controlled by $R_{1}$ or $\mathrm{R}_{2}$. Moreover, the quality factor $\mathrm{Q}$ can be controlled by the ratio of $R_{2} / R_{1}$ or $C_{3} / C_{4}$. Note that, if $V_{i 3}=0$ and $V_{i 1}=V_{i 2}=V_{i n}$, a second-order lowpass filter can be obtained from $V_{o 2}$ with matching condition $C_{3} R_{2}$ $=2 C_{4} R_{1}$.

Five kinds of biquad filters obtained from $\mathrm{V}_{\mathrm{oI}}$ and $\mathrm{V}_{\mathrm{o} 2}$, concerning Circuit $\mathrm{A}, \mathrm{B}$, and $\mathrm{C}$, are listed in Table 1. From Table 1, one can see that the highpass, bandpass, lowpass, notch and allpass filters can be synthesized from the same output terminal $V_{o 1}$. However, the output terminal $\mathrm{V}_{02}$ can provide only highpass, bandpass, and lowpass filters. The filters require no matching condition except for few applications of $\mathrm{V}_{\mathrm{o} 2}$ Similarly, if the $\mathrm{RC}$ elements of Circuit $B$ are exchanged, another universal filter can also be obtained. The transfer functions, natural frequeney $\omega_{0}$, and the quality factor $Q$ are the same as those of Equations (5a), (5b), and (5c).

\section{Sensitivities}

Taking into account the nonideal CCIIs, there are two nonideal factors $\alpha=1 \pm \varepsilon_{1} \quad\left(\varepsilon_{1}\right.$ denotes the current tracking error from port $x$ to port $z$ ) and $\beta=1 \pm \varepsilon_{2}\left(\varepsilon_{2}\right.$ denotes the voltage tracking error from port $\mathrm{y}$ to port $\mathrm{x}$ ). Note that $\varepsilon_{1}$ and $\varepsilon_{2}$ are frequency-dependent compound functions. At low frequency they are real, and exhibit magnitudes that are much lower than unity $\left(\varepsilon_{1}<<1\right.$, $\varepsilon_{2}<<1$ ). The port relations of a nonideal CCII can be given by $i_{z}= \pm \alpha i_{x}$, and $v_{x}=\beta v_{y}$. Hence the natural frequency $\omega_{0}$ and the quality factor $Q$ of Circuit A become

$$
\begin{gathered}
\omega_{0}=\sqrt{\frac{\left(1+\alpha_{1}\right)}{\alpha_{1} \alpha_{2} \beta_{1} \beta_{2} C_{1} C_{2} R_{3} R_{4}}} \\
Q=\sqrt{\frac{\alpha_{1} C_{1} R_{4}}{\left(1+\alpha_{1}\right) \alpha_{2} \beta_{1} \beta_{2} C_{2} R_{3}}}
\end{gathered}
$$

The active and passive sensitivities are

$$
\begin{gathered}
\mathrm{S}_{\mathrm{C}_{1}, \mathrm{R}_{4}}^{\mathrm{Q}}=-\mathrm{S}_{\alpha_{2}, \beta_{1}, \beta_{2}, \mathrm{C}_{1}, \mathrm{C}_{2}, \mathrm{R}_{3}, \mathrm{R}_{4}}^{\omega_{0}}=-\mathrm{S}_{\alpha_{2}, \beta_{1}, \beta_{2}, \mathrm{C}_{2}, \mathrm{R}_{3}}^{\mathrm{Q}}=\frac{1}{2} \\
\mathrm{~S}_{\alpha_{1}}^{\omega_{0}}=-\mathrm{S}_{\alpha_{1}}^{\mathrm{Q}}=-\frac{1}{2}\left(\frac{1}{1+\alpha_{1}}\right)
\end{gathered}
$$

all of which are small since a value is approximately equal to 1 . Hence, the proposed universal filters are insensitive to the passive elements they used.

\section{Simulation Results}

In PSpice simulation, AD844 ICs from Analog Devices have been used to implement CCIIs. To evaluate the performance of the Circuit $\mathrm{A}$, consider the typical values for passive elements: $C_{1}=C_{2}=1 n F, R_{3}=$ $1 \mathrm{k} \Omega$, and $\mathrm{R}_{4}=2 \mathrm{k} \Omega$. This choice leads to $f_{0}=159.2 \mathrm{kHz}$, and $Q=1$. Fig.4(a) shows the frequency responses of the highpass, bandpass, and lowpass filters obtained from $\mathrm{V}_{\mathrm{o} 1}$ of Circuit A. Circuit $\mathrm{B}$ is demonstrated by choosing $\mathrm{C}_{1}=\mathrm{C}_{2}=1 \mathrm{nF}, \mathrm{R}_{3}=1 \mathrm{k} \Omega$, and $\mathrm{R}_{4}=2 \mathrm{k} \Omega$. Fig.4(b) shows the frequency responses of the notch filter obtained from $\mathrm{V}_{\mathrm{o} 1}$ and lowpass filter obtained from $\mathrm{V}_{\mathrm{o} 2}$ of Circuit $\mathrm{B}$. The gain and phase responses of allpass filter obtained from $V_{\circ 1}$ of Circuit $C$ are shown in Fig 4 (c) with $C_{3}=C_{4}$ $=\operatorname{lnF}, \mathrm{R}_{1}=0.5 \mathrm{k} \Omega$, and $\mathrm{R}_{2}=1 \mathrm{k} \Omega$. This choice also leads to $f_{0}=159.2 \mathrm{kHz}$, and $\mathrm{Q}=1$. The simulation results are in excellent agreement with the theoretical analysis.

\section{Conclusion}

A novel configuration for realizing voltage-mode universal filters with three inputs and two outputs is presented. The proposed configuration uses only two second-generation current conveyors and four passive elements. A number of voltage-mode univęrsal filters can be developed from the configuration. The universal filters can realize the highpass, bandpass, lowpass, notch, and allpass filters without changing circuit topology and elements. The proposed configuration provides the following advantages: (i) a number of universal filters can be developed from the configuration, (ii) minimum active and passive elements, (iii) realizing the highpass, bandpass, lowpass, notch, and allpass filters without changing circuit topology and elements, (iv) low active and passive sensitivities. The universal filters require no matching condition except for few applications. All simulation results verified the theoretical analysis. 


\section{References}

[1] Wilson, B., "Recent developments in current conveyors and current mode circuits", IEE Proc. G, Circuit Devices Syst., 137, (2), pp.63-77, 1990.

[2] Ozoguz, S., and Gunes, E. O.," Universal filter with three inputs using CCII+" , Electron. Lett. 32, pp.2134-2135, 1996.

[3] Chang, C. M. and Lee, M.S., "Comment: Universal voltage-mode filter with three inputs and one output using three current conveyors and one voltage follower", Electron. Lett., 31, pp.353, 1995.

[4] Liu, S. -I., "Universal filter using two currentfeedback amplifiers", Electron. Lett., 31, pp.629-630, 1995.

[5] Abuelma'atti, M.T. and Al-Shahrani, S. M., "New universal filter using two current-feedback amplifiers ",INT. J. Electronics, 80, pp.753-756, 1996.

[6] Liu, S.-I., and Lee, J. -L., "Insensitive current/ voltage-mode filters using FTFNs", Electron. Lett., 32, pp.1070-1080, 1996.

[7] liu. S. -I., and Lee. J. -L., "Voltage-mode universal filter using two current conveyors", INT, J, Electronics., 82,pp.145-149, 1997.

[8] Horng, J. -W., Lee, M. -H., Chen, H. -C., and Chang, C. -W.," New CCII-based universal filter using two current conveyors", INT. J. Electronics. 82, pp.151-155, 1997.

[9] Horng, J. -W., Tsai, C. -C., and Lee, M. -H," Novel universal voltage biquad filter with three inputs and one output using only two current conveyors", INT. J. Electronics. ,80, pp.543-546., 1996.

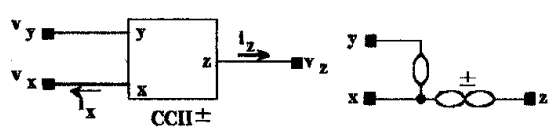

Fig. 1 Symbol and nullor model of $\mathrm{CCII} \perp$

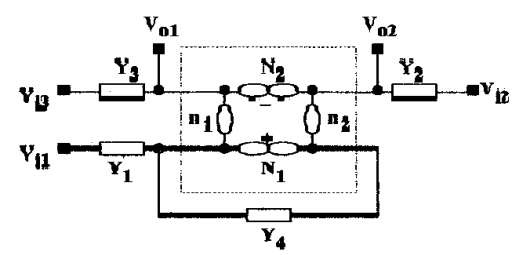

Fig. 2 Configuration for realizing voltage-mode universal biquad filter

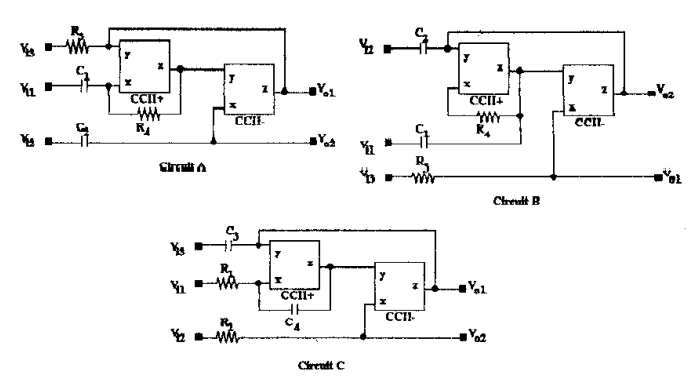

Fig. 3 Proposed voltage-mode universal biquad filters (Circuit A, B, and C)

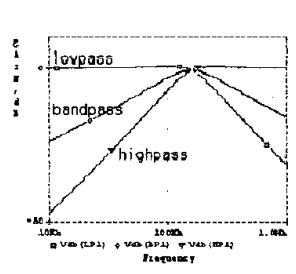

$4(a)$

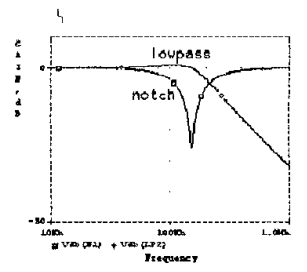

4(b)

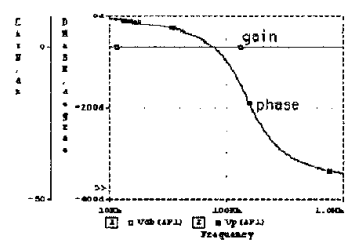

$4(c)$

Fig. 4 Simulation results of (a)highpass, lowpass, and bandpass responses from $V_{01}$ of Circuit $A$ (b) notch filter from $V_{01}$ and lowpass filter from $V_{02}$ of Circuit $B$ (c) gain and phase responses of allpass filter from $V_{01}$ of Circuit C.

\begin{tabular}{|c|c|c|c|c|c|c|}
\hline \multirow[t]{2}{*}{$V_{i 1}$} & \multirow[t]{2}{*}{$V_{i a}$} & \multirow[t]{2}{*}{$V_{i 3}$} & \multicolumn{2}{|c|}{ Circuit A (or B) } & \multicolumn{2}{|c|}{ Circuit C } \\
\hline & & & $V_{\mathrm{ol}}$ & $V_{\mathrm{s} 2}$ & $V_{o 1}$ & $V_{02}$ \\
\hline$V_{\text {in }}$ & 0 & 0 & HP & $\mathrm{BP}$ & LP & $\mathrm{BP}$ \\
\hline 0 & $V_{i n}$ & 0 & BP & - & $B P$ & - \\
\hline 0 & 0 & $V_{\text {in }}$ & LP & - & $\mathrm{HP}$ & - \\
\hline$V_{\text {in }}$ & 0 & $V_{\text {in }}$ & notch & LP & notch & HP \\
\hline$V_{i}$ & $-V_{\text {in }}$ & $V_{\text {in }}$ & $\mathrm{AP}$ & - & $\mathrm{AP}$ & - \\
\hline $\mathrm{V}_{\mathrm{m}}$ & $\mathrm{v}_{\mathrm{m}}$ & 0 & $\cdot$ & ${ }^{*} \mathrm{HP}$ & - & ${ }^{* *} \mathrm{LP}$ \\
\hline
\end{tabular}

$\mathrm{HP}=$ highpass, $\mathrm{BP}$-bandpass, $\mathrm{LP}=$-lowpass, $\mathrm{AP}=$-allpass *matching condition: $\mathrm{C}_{1} \mathrm{R}_{4}=2 \mathrm{C}_{2} \mathrm{R}_{3}$

**matching condition: $\mathrm{C}_{3} R_{2}=2 \mathrm{C}_{4} \mathrm{R}_{1}$

Table 1. Five types of biquad filters obtained from $V_{01}$ and $\gamma_{02}$ concerning Cirvuit $A, B$, and $C$. 